\title{
Trade Opening and the Behavior of Emerging Stock Market Prices
}

\author{
Parantap Basu \\ Fordham University \\ Matthew R. Morey \\ Pace University
}

\begin{abstract}
In this paper we develop a model that explores the effect of trade openness on stock price behavior. The model predicts that stock returns show non-zero serial correlation in a closed economy. However, once the country opens on the trade front, the stock returns show zero serial correlation. The reason for the difference is that once the country opens itself to trade, the growth process becomes selfsustained due to optimal use of imported intermediate inputs. Stock prices reflect this gain in productive efficiency by displaying a random walk behavior. The model also establishes that financial opening alone without trade opening will not lead to gain in efficiency in the stock prices.
\end{abstract}

- JEL Classification: G12, F41

- Key words: Trade Liberalization, Emerging Stock Markets, Stock Market Efficiency, Trade Openness

\section{Introduction}

In the 1990s, the number of people who lived in open, market-oriented economies was the highest since the beginning of the twentieth century. In a well-

\footnotetext{
*Corresponding address: Parantap Basu, Department of Economics Fordham University Bronx, NY 10458. Phone: 714-817-4061 Fax: 718-817-3518 Email: Basu@fordham.edu

Matthew R. Morey, Department of Finance Lubin School of Business, 1 Pace Plaza, Pace University, New York, NY 10038. Phone: 212-346-1796 E-mail: mmorey@pace.edu

(C2005-Center for International Economics, Sejong Institution, All Rights Reserved.
} 
cited paper, Sachs and Warner (1995) documented this fact by showing that in 1994, about 50 percent of the world's population lived in countries with open, market oriented economic systems. By comparison, in 1960, only 20 percent of the world lived in nations with such policies.

Nowhere has this change been more important than in emerging market nations. In reaction to years of slow growth, these countries have abandoned state oriented philosophies of import substitution, nationalization, and deficit financing for policies such as trade opening, privatization, and macroeconomic stabilization. Furthermore, these reforms have not just been economic in nature. Financially, these countries have also liberalized--taking major steps to liberalize banking and to open up stock markets to foreign capital.

In response to these changes, a number of researchers e.g., Bekaert and Harvey (2000), Bekaert, Harvey and Lunblad (2001), Henry (2000a, 2000b), Kim and Singal (2000), and Levine et al. (2000), have examined the empirical effects of the economic and financial reforms on emerging market stock prices. In general, they find that liberalization has important, positive effects: stock prices increase without commensurate increases in volatility, the efficiency of the stock market improves, and no evidence appears of an increase in inflation rates or an appreciation of exchange rates.

However, despite the growing amount of empirical work on the effects of these reforms, little or no theoretical analysis has been made to understand the effect of liberalization on stock return autocorrelation properties. This is an important question because when real and financial sectors are interrelated, increased productive efficiency in the real sector due to economic liberalization is bound to impact the extent of financial market efficiency measured in terms of autocorrelation in real stock returns. Indeed, in standard finance textbooks, we learn about various forms of market efficiency; however, little efforts have been made to relate the technological efficiency due to various liberalization programs to the financial market efficiency.

In this paper we hope to fill this void. We develop a model that explores the effect of trade openness on stock price behavior in terms of an open economy asset pricing model in the tradition of Bardhan (1970) and Bruno and Sachs (1985). The model predicts that stock returns will show non-zero serial correlation in a closed economy. However, once the country opens on the trade front, the stock returns will show zero serial correlation. The reason for the difference is that once the country opens itself to trade, it can use imported intermediate inputs optimally, 
which was not possible in a closed economy.

In our model, intermediate inputs are non-rival in nature. These inputs may be viewed as blueprints of new technology, which directly impacts the home country's total factor productivity. ${ }^{1}$ Given a limited capacity of the infrastructure, the government in a closed economy optimally plans the production of these inputs and makes it available to the private sector using a marginal cost pricing rule. The private sector in a closed economy faces a rigid quantity constraint on these intermediate inputs, which gives rise to diminishing returns to physical capital.

In an open economy all these inputs are imported from abroad and financed by short-term loans from international credit agencies. Trade openness is thus viewed as removal of a non-tariff barrier or alternatively, a relaxation of a quantity constraint. After trade opening, home country can make efficient use of intermediate inputs, which complement physical capital. The resulting gain in productive efficiency makes the growth process self-sustained. The self-sustained growth process thus translates into random walk behavior in the stock prices as the stock prices reflect the value of capital.

We also analyze the effect of financial opening on the stock price behavior. An important implication of the model is that the trade opening in the form of removal of barriers to imported inputs is crucial for stock market efficiency. Without this kind of trade openness, financial liberalization alone will not lead to gain in stock market efficiency.

The paper is organized as follows. In section II, we lay out the models of asset pricing for both closed and open economies. We then characterize the asset return properties in a rational expectations equilibrium for alternative regimes of liberalization. Section III analyzes the effect of financial openness on the stock price behavior. Section IV briefly discusses the some empirical work on emerging stock market efficiency and then relates this work to our own theoretical conclusions described in sections II and III. Finally, Section V concludes the paper.

\section{The Model}

The model has two important features. First, it shows explicitly the relationship between the real and financial sectors of a quantity constrained economy by

${ }^{1}$ Feenstra and Markusen (1994) argue that the growth of output can result from the use of wider range of intermediate goods in production. 
integrating a stochastic growth model with the asset pricing equation along the lines suggested by Brock (1982). Second, the model stresses the role of intermediate imports as a supply-side constraint resembling Bardhan (1970) and Bruno and Sachs (1985).

Consider a representative home country with an infinitely lived household, which makes decision about consumption $\left(C_{t}\right)$, and saving in each period. All households' savings are in the form of investment in home country's stock market only. There is no offshore holding of home country's shares. Home country's stock market is entirely closed to the foreigners. ${ }^{2}$ Each share thus represents a claim to the home country's capital stock. The representative home consumer thus behaves like a Lucas (1978) household. At date $t$, the household enters with $Z_{t}$ shares purchased in the previous period, which yields dividend $D_{t}$ per unit of share and a capital gain from selling these shares. Formally, the households problem is:

$$
\operatorname{Max} \mathrm{E}_{0} \sum_{t=0}^{\infty} \beta^{t} U\left(C_{t}\right)
$$

s.t. $P_{t} Z_{t+1}-P_{t-1} Z_{t}=D_{t} Z_{t}+\left(P_{t}-P_{t-1}\right) Z_{t}-C_{t}$

where $\beta \in(0,1)=$ the subjective discount factor, and $\mathrm{P}_{\mathrm{t}}=$ ex-dividend price of shares at date t. Further, the total supply of shares is inelastic and normalized at the unit level. The households first order condition is:

$$
P_{t} U^{\prime}\left(C_{t}\right)=\beta E_{t}\left[U^{\prime}\left(C_{t+1}\right)\left(P_{t+1}+D_{t+1}\right)\right]
$$

This valuation equation simply states the fact that the consumer chooses a consumption path in such a way that the utility value of the purchase price of a share exactly equals the discounted utility value of the selling price, $\mathrm{P}_{t+1}$, plus the dividend, $\mathrm{D}_{\mathrm{t}+1}$.

Next we consider the production sector of the economy. The firm owns the capital stock, produces, and invests. For production, the firm uses the private capital stock and a publicly available non-rival intermediate input, $\mathrm{V}_{\mathrm{t}}$. This input is provided by a public agency at a user price, $\mathrm{Q}_{\mathrm{t}}$.

\footnotetext{
${ }^{2}$ In this section, we analyze the effect of trade opening and not financial opening, and therefore, we ignore offshore holding of assets. In section III, we deal with the effect of financial opening. Moreover, to keep the model simple, we ignore here any trade in final goods. Appendix 2 outlines a two country model allowing trade in final goods.
} 
In a closed economy, there is a state monopoly over the production of these intermediate inputs. Because of poor public sector infrastructure only a limited quantity, $\overline{\mathrm{V}}$ of these inputs can be produced. These intermediate inputs are efficiently priced; its price, $\mathrm{P}_{\mathrm{vt}}$ equals its marginal product $\left(\mathrm{MPV}_{\mathrm{t}}\right)$. The government then auctions off these inputs to the firms at a user price, $Q_{t}$ and then rebates the net surplus, $\left(\mathrm{Q}_{\mathrm{t}}-\mathrm{P}_{\mathrm{vt}}\right) \mathrm{V}_{\mathrm{t}}$, to the firms as a lump-sum (call it $\mathrm{T}_{\mathrm{t}}$ ).

Once the home country opens up on the trade front, this quantity constraint on the imported intermediate inputs disappears for the following reasons. The home country now finances the optimal purchase of intermediate inputs by short term loans from international credit agencies at a fixed world interest rate, $r{ }^{*}{ }^{3}$ Since the optimal choice of intermediate input is a static decision, the loan the home country takes at start of each period to finance is repaid at the end of the period with interest. The price of the intermediate input, $\mathrm{P}_{\mathrm{vt}}$ thus equals the world interest rate, $\mathrm{r}^{*}$. As a result, the home country now faces a perfectly elastic supply curve for intermediate inputs at a fixed world interest rate, $\mathrm{r}^{*}$. The government purchases the optimal level of intermediate inputs, $\mathrm{V}_{\mathrm{t}}{ }^{*}$ such that $\mathrm{MPV}_{\mathrm{t}}=\mathrm{r}^{*}$. The rest of the story stays the same. The government charges a user price, $Q_{t}$ and rebates the surplus $\left(Q_{t}-r^{*}\right) . V_{t}^{*}$ to the firms as lump-sum. It is important to note that the home country's stock market is still closed to off-shore investors and therefore, the domestic share continues to be a claim to home country's own capital stock alone. ${ }^{4}$

Note that for a closed economy, the government imposed quantity constraint, $\overline{\mathrm{V}}<\mathrm{V}_{t}^{*}$. Therefore, a closed country cannot reap full economies of scale by choosing the intermediate input at the efficient level $\mathrm{V}_{\mathrm{t}}{ }^{*}$. Figure 1 pictures these two regimes of liberalization given a fixed realization of $\varepsilon_{t}{ }^{5}$

Given the sequences $\left\{V_{t}\right\},\left\{Q_{t}\right\}$ and $\left\{T_{t}\right\}$, the representative firm solves the following maximization problem.

$$
\operatorname{Max}_{\left\{K_{t}\right\}} E_{0} \sum_{t=0}^{\infty}\left[\varepsilon_{t} F\left(K_{t}, V_{t}\right)-Q_{t} V_{t}-I_{t}+T_{t}\right] \prod_{t=0}^{t} d_{i}
$$

\footnotetext{
${ }^{3}$ This access to outside financing is made possible due to various structural adjustments loan programs of the World Bank once countries open the trade front. We do not address the issues of creditability and default risk.

${ }^{4}$ Since our central theme of this paper is to understand the effect of economic liberalization not financial liberalization, we disallow in this model any offshore holding of domestic stocks.

${ }^{5}$ In principle, an open economy can transit between closed and open states. In this paper, we rule out this possibility by imposing restriction on the lower bound of $\varepsilon_{\mathrm{t}}$ (see equation (2.5)).
} 
s.t. $I_{t}=K_{t+1}-(1-\delta) K_{t}$, and $K_{0}=$ given.

where $\mathrm{K}_{\mathrm{t}}=$ capital stock at the beginning of period $\mathrm{t}, \mathrm{I}_{\mathrm{t}}=$ gross investment in period $\mathrm{t}, \varepsilon_{\mathrm{t}} \in[\mathrm{a}, \mathrm{b}]$ is an idiosyncratic productivity shock to the total factor productivity realized at the beginning of period $t, \delta \in(0,1)$ is the rate of depreciation of the capital, $\mathrm{F}\left(\mathrm{K}_{\mathrm{t}}, \mathrm{V}_{\mathrm{t}}\right)$ is a constant returns to scale production function with the usual properties: $F_{k}>0, F_{v}>0, F_{k k}<0, F_{k v}>0$ and $F_{v v}<0$, where the subscripts denote the arguments of differentiation. We assume that both $\mathrm{V}_{\mathrm{t}}$ and $\mathrm{K}_{\mathrm{t}}$ are necessary inputs in the production process in the sense that $F\left(K_{t}, 0\right)=0$ and $F\left(0, V_{t}\right)$ $=0$. The term

$\prod_{i=1}^{t} d_{i}$, represents the stochastic discount factor of the firm at date t. Notice that the discount factor is time varying and it is endogenously determined.

The fundamental source of uncertainty emanates from the technology along the lines of a real business cycle model, i.e., the productivity shock, $\varepsilon_{\mathrm{t}}$ arises from exogenous technological innovations or vagaries of weather. ${ }^{6}$ In order to rule out an open economy transiting between closed and open states, we assume that the lowest bound, $a$ for $\varepsilon_{\mathrm{t}}$ satisfies the following restriction:

$$
\bar{V}<K_{0} h^{-1}\left(\frac{r^{*}}{a}\right)
$$

where

$$
h\left(\frac{V_{t}}{K_{t}}\right)=F_{v}\left(1, \frac{V_{t}}{K_{t}}\right)
$$

The inequality restriction (2.4) ensures that even if the open economy suffers the worst shock, its optimal choice of foreign input, $\mathrm{V}_{\mathrm{t}}{ }^{*}$ still exceeds the closed economy's fixed supply, $\overline{\mathrm{V}}$. The appendix discusses the rationale behind the inequality (2.5) further.

\section{A. Characterization of a Rational Expectations Equilibrium (REE)}

REE(i) Facing $\left\{\mathrm{P}_{\mathrm{t}}\right\},\left\{\mathrm{D}_{\mathrm{t}}\right\}$, the household solves its decision problem, $(2 . \mathrm{H})$, and chooses $\left\{\mathrm{C}_{\mathrm{t}}\right\},\left\{\mathrm{Z}_{\mathrm{t}}\right\}$; REE(ii) Facing $\left\{\varepsilon_{\mathrm{t}}\right\},\left\{\mathrm{d}_{\mathrm{t}}\right\},\left\{\mathrm{V}_{\mathrm{t}}\right\},\left\{\mathrm{T}_{\mathrm{t}}\right\},\left\{\mathrm{Q}_{\mathrm{t}}\right\}$, the firm solves its

\footnotetext{
${ }^{6}$ In real business cycle models, this productivity uncertainty is attributed to exogenous technological innovations or vagaries of weather. In addition, one may also attribute the production uncertainty to an unpredictable change in tax policy.
} 
present value maximization problem, (2.F). In a closed economy facing a fixed supply $\overline{\mathrm{V}}$ of intermediate inputs, it chooses $\left\{\mathrm{K}_{\mathrm{t}}\right\}$. In an open economy, facing a fixed world interest rate, $\mathrm{r}^{*}$, it chooses $\left\{\mathrm{V}_{\mathrm{t}}^{*}\right\}$ such that $\varepsilon_{\mathrm{t}} \mathrm{F}_{\mathrm{v}}\left(\mathrm{K}_{\mathrm{t}}, \mathrm{V}_{\mathrm{t}}\right)=\mathrm{r}^{*}$.

REE(iii) The discount factor, $\left\{d_{t}\right\}$, is consistent with the households intertemporal marginal rate of substitution in consumption, i.e., $d_{t+1}(\varepsilon)=\beta U^{\prime}\left(C_{t+1}(\varepsilon)\right) / U^{\prime}\left(C_{t}\right)$;

REE(iv) The government budget balances, i.e., $T_{t}=\left(Q_{t}-P_{v t}\right) V_{t}{ }^{7}$

REE(v) In a closed economy with a fixed supply of intermediate inputs, the price of intermediate inputs adjusts to clear the market meaning $P_{v t}=F_{v}\left(K_{t}, \overline{\mathrm{V}}\right)$. In an open economy, $P_{v t}=\mathrm{r}^{*}$.

REE(vi). Asset market clears, i.e., $\mathrm{Z}_{\mathrm{t}}=1$.

Proposition 1: The solution to the aforementioned REE can be obtained by solving the following social planning problem:

$$
\begin{aligned}
& \operatorname{Max} E_{0} \sum_{t=0}^{\infty} \beta^{t} U\left(C_{t}\right) \\
& \text { s.t. } C_{t}+K_{t+1^{-}}(1-\delta) K_{t}=H\left(K_{t}, V_{t}, \varepsilon_{t}\right) \\
& \text { where } H\left(K_{t}, V_{t}, \varepsilon_{t}\right)=\varepsilon_{t} F\left(K_{t}, V_{t}\right)-P_{v t} V_{t}
\end{aligned}
$$

Proof: In equilibrium, a fixed number shares is traded (which is normalized at unit level). Hence, the households budget constraint in problem $(2 . \mathrm{H})$ reduces to:

$C_{t}=D_{t}$.

Next, notice that the dividend distributed to the household is nothing but the firm's cash flow in (2.F). In other words,

$D_{t}=\varepsilon_{t} F\left(K_{t}, V_{t}\right)-Q_{t} V_{t}-I_{t}+T_{t}$

Using the government budget balance condition, REE(iv), (2.9) reduces to:

$D_{t}=\varepsilon_{t} F\left(K_{t}, V_{t}\right)-P_{v t} \cdot V_{t}-I_{t}$

which upon substitution in (2.8) yields the resource constraint (2.6) of the social planner. //

\section{B. Return Behavior for a Closed Economy}

In a closed economy, the private sector is subject to the following quantity constraint on the availability of intermediate inputs.

$$
V_{t} \leq \bar{V}
$$

\footnotetext{
${ }^{7}$ Since the government rebates all the surplus to the firms, the REE allocation of output between consumption and savings is not affected by the stochastic process for the user price, $Q_{t}$. As a result, the equilibrium asset prices and returns are also independent of $\mathrm{Q}_{\mathrm{t}}$.
} 
We now examine the equilibrium real equity return behavior for an economy where the quantity constraint (2.11) is binding. We have the following lemma.

Lemma 1: In a rational expectations equilibrium, ex post stock return equals the investment return meaning,

$$
\frac{P_{t+1}+D_{t+1}}{P_{t}}=F_{k t+1}+1-\delta
$$

Proof: Since the production function is subject the constant returns to scale property and the imported intermediate inputs are paid according to its marginal product, in equilibrium, the price of equity $\left(\mathrm{P}_{t}\right)$ equals the claim to the capital stock, $\mathrm{K}_{\mathrm{t}+1}$ purchased at $\mathrm{t}$. In other words, in equilibrium,

$$
P_{t}=K_{t+1}
$$

Next using the cash flow in (2F), REE(iv) and the fact that $\mathrm{P}_{\mathrm{vt}}=\mathrm{MPV}_{\mathrm{t}}$, and the CRS property of the production function, the dividend at $\mathrm{t}+1$ can be rewritten as,

$$
D_{t+1}=\varepsilon_{t+1} F_{k}\left(K_{t+1}, V_{t+1}\right) K_{t+1}-I_{t+1}
$$
Plugging (2.12) and (2.13) into the ex post stock return, $\frac{P_{t+1}+D_{t+1}}{P_{t}}$,
immediately follows.

Notice that this equivalence between stock returns and investment return is a standard arbitrage condition, which holds despite the presence of a quantity constraint. The key reason for the validity of this arbitrage condition in the present context is the efficient pricing of intermediate inputs. If intermediate inputs are priced according to its marginal product, the remaining proceeds must go to the capital owners in the economy. Since equity is the value of capital, it is not surprising that the standard arbitrage condition holds.

In order to characterize the process for stock returns, we need to impose additional parametric restrictions on preference and technology. Assume a constant relative risk aversion (CRRA) class of utility functions and a Cobb-Douglas production function as follows:

$$
U\left(C_{t}\right)=\frac{C_{t}^{1-\gamma}-1}{1-\gamma}
$$


with $\gamma>0$

$$
Y_{t}=F\left(K_{t}, V_{t}\right)=K_{t}^{1-\alpha} V_{t}^{\alpha}
$$

with $0<\alpha<1$. Notice that the reciprocal of $\gamma$ defines the elasticity of intertemporal substitution (call it $\sigma$ ) and $1-\alpha$ is the capital's share in output.

We first analyze the equilibrium property of the stock return for this closed economy. Since the level of intermediate inputs is fixed and there are no exogenous sources of growth, in the absence of any uncertainty, the model has a perfect foresight steady state where all variables are time invariant and henceforth represented by an asterisk. The steady state gross investment return (call $\mathrm{R}^{*}$ ) is thus characterized as:

$$
R^{*}=\frac{1}{\beta}
$$

Since an exact closed form solution for this model economy is not possible, we resort to a loglinear approximation of the model around the perfect foresight steady state. We follow Campbell's (1994) procedure of finding an approximate analytical solution by loglinearizing the model around the model's perfect foresight steady state. Defining all lower case letters as log levels, the production function (2.16) can be written as:

$$
y_{t}=(1-\alpha) k_{t}+\alpha \bar{v}+a_{t}
$$

where $y_{t}$ is the $\log$ of output and $a_{t}=\log \varepsilon_{t}$. Following Campbell (1994), we will, henceforth suppress all the constant intercept terms in the equations. The system of loglinear difference equations can be viewed as zero mean deviations from the model's perfect foresight steady state.

Using the fact that $\mathrm{P}_{\mathrm{vt}}=M P V_{\mathrm{t}}$ as per $\mathrm{REE}(\mathrm{v})$, the social planner's resource constraint (2.6) can be written as:

$$
C_{t}+K_{t+1}-(1-\delta) K_{t}=(1-\delta) K_{t}^{1-\alpha} \bar{V}^{\alpha} \varepsilon_{t}
$$

which can be loglinearized ${ }^{8}$ as:

$$
k_{t+1} \approx \lambda_{1} k_{t}+\lambda_{2} a_{t}+\left(1-\lambda_{1}-\lambda_{2}\right) c_{t}
$$

\footnotetext{
${ }^{8}$ See Campbell (1994) for details on the log linearization. By normalizing $\bar{V}$ to unity, the present setting can be mapped into Campbell's first model with inelastic labor and zero growth. Therefore, the same solution for the elasticities $\left(\eta_{\mathrm{ij}}\right)$ apply here.
} 
where $\lambda_{1}=\mathrm{R}^{*}$

$$
\lambda_{2}=\frac{\alpha\left(R^{*}-1+\delta\right)}{1-\alpha}
$$

Next note that the first order condition of the social planner's problem (2.P) can be approximated as:

$$
r_{t+1} \approx \lambda_{3}\left(a_{t+1}-k_{t+1}\right)
$$

where

$$
\lambda_{3} \approx \frac{\alpha\left(R^{*}-1+\delta\right)}{R^{*}}
$$

We have the following proposition:

Proposition 2: In a closed economy where the availability of imported intermediate inputs is fixed as in (2.11), the equilibrium stock return and price processes are given by the following:

$$
\begin{gathered}
r_{t}=\eta_{k k} \log R_{t-1}+\lambda_{3} a_{t}-\lambda_{3}\left(\eta_{k k}+\eta_{k a}\right) a_{t-1,} \\
r=\eta_{k k} p_{t-1}+\eta_{k a} a_{t}
\end{gathered}
$$

where

$$
\begin{gathered}
\eta_{k k}=\lambda_{1}+\left(1-\lambda_{1}-\lambda_{2}\right) \eta_{c k} \\
\eta_{k a}=\lambda_{2}+\left(1-\lambda_{1}-\lambda_{2}\right) \eta_{c a} \\
\eta_{c k}=\frac{-Q_{1}-\sqrt{Q_{1}^{2}-4 Q_{0} Q_{2}}}{2 Q_{2}} \\
\eta_{c a}=\frac{-\eta_{c k} \lambda_{2}-\sigma \lambda_{2}}{-1+\left(1-\lambda_{1}-\lambda_{2}\right)\left(\eta_{c k}+\sigma \lambda_{3}\right)} \\
Q_{2}=\left(1-\lambda_{1}-\lambda_{2}\right) ; Q_{1}=\lambda_{1}-1+\sigma \lambda_{3}\left(1-\lambda_{1}-\lambda_{2}\right) ; Q_{0}=\sigma \lambda_{3} \lambda_{1}
\end{gathered}
$$

Proof: see Appendix.

Note that the stock return follows an $\operatorname{ARMA}(1,1)$ process while the stock price 
follows a stationary $\mathrm{AR}(1)$ process. The immediate implication is that stock prices are mean reverting process in a closed economy. ${ }^{9}$ It is straightforward to verify that the autocorrelation function for the stock returns in $(2.24 \mathrm{~b})$ is given by:

$$
\begin{aligned}
& \rho_{1}=\frac{-\left(1-\eta_{k k}^{2}-\eta_{k k} \cdot \eta_{k \varepsilon}\right) \eta_{k a}}{\left(1-\eta_{k k}^{2}+\eta_{k a}^{2}\right)} \\
& \rho_{j}=\eta_{k k} \rho_{j-1} \quad \text { for } \mathrm{j}>1
\end{aligned}
$$

Proposition 2 provides a key result of the paper. In a closed economy with a binding constraint on the availability intermediate inputs, return autocorrelations are generally non-zero, which means predictability of stock prices. Stock prices do not show weak-form efficiency in this closed economy. The exact sign of autocorrelations depends on the parameter values. Table 1 reports calculation of the first order autocorrelation for alternative parameter values setting $\beta=0.96$ and $\delta=.025$ as in Campbell (1994).

Notice that the return autocorrelations range from negative to positive numbers depending on the risk aversion parameter $(\gamma)$ and the technology parameter $(\alpha)$. An increase in risk aversion unambiguously raises the return autocorrelation. A higher $\gamma$ means a lower degree of intertemporal substitution $(\sigma)$ in consumption. When a good shock hits the economy today, the current output rises. This promotes both current consumption and investment. However, due to diminishing returns, increased investment lowers the prospective return to capital. In response to this, the agent experiences two opposing effects: an income effect, which induces her to invest more and a substitution effect which lowers her investment propensity. For a large value of $\gamma$ the income effect dominates the substitution effect. This will lower the investment return further. In summary, return will first rise in response to a

Table 1. Calculation of the first order autocorrelation for alternative parameter values

\begin{tabular}{ccccccc}
\hline$\alpha \backslash \gamma$ & .3 & .7 & 1 & 2 & 5 & 10 \\
\hline .3 & -.019 & -.014 & 0.00 & 0.00 & 0.036 & .086 \\
.5 & -.038 & -.024 & -.015 & .013 & .081 & .172 \\
.6 & -.052 & -.03 & -.015 & .026 & .121 & .236 \\
.8 & 0.012 & -.024 & .016 & .118 & .295 & .452 \\
\hline
\end{tabular}

\footnotetext{
${ }^{9}$ It is important to note that equilibrium stock prices show mean reverting behavior as long as $\eta_{\mathrm{kk}}<1$. Campbell has calculated $\eta_{\mathrm{kk}}$ for a wide range of parameter values and finds it less than unity. It is increasing in the risk aversion parameter, $\gamma$. In a deterministic model, $1-\eta_{\mathrm{kk}}$ represents the rate of convergence.
} 
positive transitory technology shock and then it will start falling. The stronger the diminishing returns to capital (meaning larger $\alpha$ ), the declining phase of the return will be more persistent until the economy lands in to the steady state. This will tend to make the return autocorrelations larger. This explains why the size of the return autocorrelation is greater when $\gamma$ or $\alpha$ is larger.

\section{Return Behavior for an Open Economy}

For an open economy, we first establish that the standard arbitrage condition again holds, meaning the ex post stock return equals investment return in each period. We have the following lemma.

Lemma 2: For an open economy, $\frac{P_{t+1}+D_{t+1}}{P_{t}}=F_{k t+1}+1-\delta$.

Proof: The social planner's resource constraint (2.6) for the open economy now reduces to:

$$
C_{t}+I_{t}=\varepsilon_{t+1} F\left(K_{t+1}, V_{t+1}\right)-r^{*} V_{t+1}
$$

Since in an REE, $C_{t}=D_{t}$ for all $t$, the dividend at date $t+1$ is given by:

$$
D_{t+1}=\varepsilon_{t+1} F\left(K_{t+1}, V_{t+1}\right)-r^{*} V_{t+1}
$$

which after using the CRS property of the production function reduces to

$$
D_{t+1}=\varepsilon_{t+1} F_{k}\left(K_{t+1}, V_{t+1}\right)+\left(\varepsilon_{t+1} F_{v}\left(K_{t+1}, V_{t+1}\right)-r^{*}\right) V_{t+1}-I_{t+1}
$$

Next note that when the imported input $\mathrm{V}_{\mathrm{t}+1}$ is set at its efficient level $\mathrm{V}_{\mathrm{t}+1}{ }^{*}$ as per REE(ii), its marginal product equals the price, $r^{*}$, meaning

$$
\varepsilon_{t+1} F_{v}\left(K_{t+1}, V_{t+1}\right)=r^{*}
$$

which means (2.33) now reduces to

$$
D_{t+1}=\varepsilon_{t+1} F_{k}\left(K_{t+1}, V_{t+1}\right)-I_{t+1}
$$

Next using the fact that $\mathrm{P}_{\mathrm{t}}=\mathrm{K}_{\mathrm{t}+1}$ for all $\mathrm{t}$ and following the same steps as in proposition 2 , it follows that 


$$
\frac{P_{t+1}+D_{t+1}}{P_{t}}=F_{k t+1}+1-\delta
$$

Proposition 3: In an open economy, stock returns show zero serial autocorrelation, and the stock price follows the random walk hypothesis.

Proof: Appendix.

The intuition behind this result is as follows. In a closed economy, home country's production is subject to diminishing returns with a fixed quantity of intermediate inputs. In an open economy, along its growth path, the home country now no longer faces any shortage of imported intermediate inputs. The level of imported intermediate inputs now grows on par with the capital stock ensuring full productive efficiency. Consequently, the return to capital does not fall as the economy grows thus giving rise to self-sustained growth. The variation of the returns to capital, therefore, purely reflects the idiosyncratic shocks $\left(\varepsilon_{t}\right)$ to productivity. The equilibrium stock returns thus show zero serial correlation and stock prices follow a random walk.

\section{Effect of Financial Opening on the Stock Market Prices}

Until now we did not allow any offshore holding of assets by the home country. In this section, we analyze a scenario where the home country is allowed to hold foreign assets. The representative agent enters each period with previous holdings of home and foreign assets. Home assets are in the form of home shares, $Z_{t}$ and foreign assets are in the form of foreign bonds, $B_{t}$ which offer a fixed world interest rate, $r^{*}$. The finance constraint facing the household is now:

$$
B_{t+1}-B_{t}+P_{t} Z_{t+1}-P_{t-1} Z_{t}=r^{*} B_{t}+D_{t} Z_{t}+\left(P_{t}-P_{t-1}\right) Z_{t}-C_{t}
$$

The first order condition for each asset is given by:

$$
\begin{gathered}
E_{t} R_{t+1} m_{m+1}=1 \\
E_{t}\left(1+r^{*}\right) m_{m+1}=1
\end{gathered}
$$

where $R_{t+1}=\frac{P_{t+1}+D_{t+1}}{P_{t}}$ and $m_{t+1}=\frac{B U^{\prime}\left(C_{t+1}\right)}{U^{\prime}\left(C_{t}\right)}$

Combining (3.2) and (3.3), we obtain the following equation for the excess return 
on stocks ${ }^{10}$ :

$$
E_{t} R_{t+1}-\left(1+r^{*}\right)=-\frac{\operatorname{cov}_{t}\left(R_{t+1}, m_{t+1}\right)}{E_{t} m_{t+1}}
$$

In order to have efficient market condition, it is necessary that the martingale efficiency condition holds, which requires the expected stock return to be constant. We next have the following proposition.

Lemma 3: If the utility function is of a CRRA class as in (2.15), the stock price follows the martingale property, if and only if the dividend growth rates are serially uncorrelated.

Proof: For the CRRA preference (2.15), in equilibrium,

$$
\begin{aligned}
& R_{t+l}=\text { constant } . \\
& \text { and }
\end{aligned}
$$

$$
m_{t+1}=\text { const. }\left[\frac{D_{t+1}}{D_{t}}\right]^{-\gamma}
$$

Next plug (3.5) and (3.6) into (3.4), to check that $E_{t}\left(R_{t+1}\right)$ is a constant if and only if dividend growth rates, $\left\{D_{t+1} / D_{t}\right\}$ are uncorrelated. Since $E_{t}\left(R_{t+1}\right)$ is a constant and the dividend growth rates are serially uncorrelated, the immediate implication is that stock prices follow the martingale property. Q.E.D.

Whether stock valuation equations satisfy market efficiency condition crucially boils down to whether dividend growth rates are serially uncorrelated. ${ }^{11}$ In the earlier section, we established that dividend growth rates would be serially uncorrelated in an economy where there is no restriction on imports of intermediate inputs. In an economy with restriction on imports, this zero correlation in dividend growth condition will be violated, and then stock prices will not obey the martingale efficiency condition even though there is financial openness. ${ }^{12}$ Financial opening

\footnotetext{
${ }^{10}$ To see this, note that (3.2) can be rewritten as: $\mathrm{E}_{\mathrm{t}} \mathrm{R}_{\mathrm{t}+1} \cdot \mathrm{E}_{\mathrm{t}} \mathrm{m}_{\mathrm{t}+1}+\operatorname{cov}_{\mathrm{t}}\left(\mathrm{R}_{\mathrm{t}+1}, \mathrm{~m}_{\mathrm{t}+1}\right)=1$. Using this in conjunction with (3.3), one gets the result.

${ }^{11}$ Note that the martingale efficiency condition is equivalent to the random walk property of stock prices. See, Basu (1990), for a general theory of martingale model of stock prices, where dividend follows a geometric random walk.

${ }^{12}$ See equations (2.24a) and (2.24b).
} 
alone will not thus promote stock market efficiency unless trade openness in the form described in section 3 is accompanied with it. This kind of trade openness promotes technological efficiency, which translates into stock market efficiency.

\section{Review of Empirical Work in relation to the Model}

As stated in the introduction, there is a growing empirical literature that has examined the role of liberalization and its influences on emerging stock markets. Given that our model, described in sections II and III, posits that after trade liberalization stock prices should eventually move to a random walk process, we now review this empirical literature and examine how it relates to our theoretical conclusions.

The results of empirical work that directly examine the issue of liberalization and stock market efficiency are in two camps. First, Kim and Singal (2000a, 2000b) have found that after financial liberalization, there is an improvement in stock market efficiency. Specifically they find using variance ratio analysis, that before liberalization most countries in the sample are not efficient (as measured by a random walk), yet after liberalization, significantly more countries cannot reject the hypothesis of a random walk. This result is very consistent with our models prediction, even though they are examining financial liberalization rather than trade liberalization.

In the other camp, Kawakatsu and Morey (1999a, 1999b) and Basu, Kawakatsu and Morey (2000) conduct a broad battery of econometric tests to examine stock market efficiency pre and post financial and trade liberalization. Using autocorrelation tests, variance ratio tests, KPSS tests, and various forms of DickeyFuller unit root tests they find that the stock markets were in general, efficient

Figure 1. Two regimes of liberalization given a fixed realization of $\varepsilon_{\mathrm{t}}$. In the Closed regime, the country remains at $\bar{V}$ In the Open regime, the country moves to $V_{t}^{*}$.

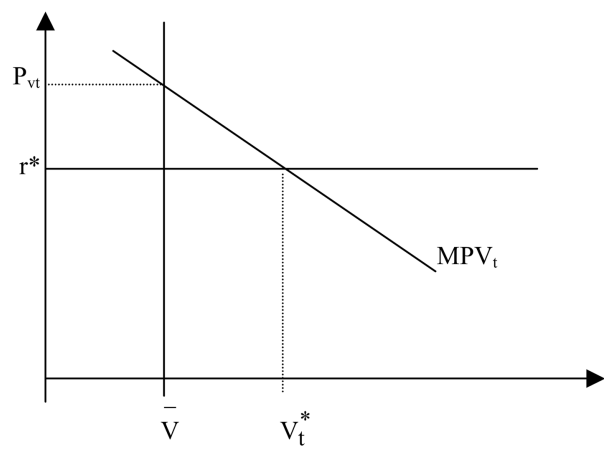


before and after liberalization (whether financial or trade).

In the same sprit as the above described work, we conducted some simple tests on real stock prices before and after trade liberalization to further examine this issue. In the analysis, we used the trade liberalization dates of Sachs and Warner (1995) to define whether a country was open or not to trade..$^{13}$ The dates of the data

Table 2. Sachs and Warner (1995) dates

\begin{tabular}{|c|c|}
\hline Closed Countries & Return Data when Closed \\
\hline Argentina & $76.01-90.12$ \\
\hline Brazil & $76.01-90.12$ \\
\hline India & $76.01-93.12$ \\
\hline Mexico & $76.01-85.12$ \\
\hline Nigeria & $85.01-99.08$ \\
\hline Pakistan & $85.01-99.08$ \\
\hline Philippines & $85.01-87.12$ \\
\hline Venezuela & $85.01-88.12$ \\
\hline Zimbabwe & $76.01-99.08$ \\
\hline Open Countries & Return Data When Open \\
\hline Argentina & 91.01-99.08 \\
\hline Brazil & $91.01-99.08$ \\
\hline Chile & $76.01-99.08$ \\
\hline Colombia & $86.01-99.08$ \\
\hline Czech. & $94.01-99.08$ \\
\hline Greece & $76.01-99.08$ \\
\hline Hungary & $94.01-99.08$ \\
\hline India & $94.01-99.08$ \\
\hline Indonesia & $90.01-99.08$ \\
\hline Jordan & $79.01-99.08$ \\
\hline Korea & $76.01-99.08$ \\
\hline Malaysia & $85.01-99.08$ \\
\hline Mexico & $86.01-99.08$ \\
\hline Morocco & $95.12-99.08$ \\
\hline Peru & $93.01-99.08$ \\
\hline Philippines & $88.01-99.08$ \\
\hline Poland & $94.01-99.08$ \\
\hline Portugal & $86.02-99.03$ \\
\hline South Africa & $94.02-99.08$ \\
\hline Sri Lanka & $93.01-99.08$ \\
\hline Taiwan & $85.01-99.08$ \\
\hline Thailand & $76.01-99.08$ \\
\hline Turkey & $89.01-99.08$ \\
\hline Venezuela & $89.01-99.08$ \\
\hline
\end{tabular}

\footnotetext{
${ }^{13}$ Sachs and Warner define a country as open or not to trade by using definitions such as whether non-tariff barriers covering 40 percent of more of trade; Average tariff rates of 40 percent or more ; a black market exchange rate that has depreciated by 20 percent or more relative to the official exchange rate, on average, during the 1970's and 1980's; and other measures. See Sachs and Warner for more information.
} 
and the listing of the countries defined as open or closed are listed in Table 2. We then used real stock prices in our analysis to be consistent with the model. The real stock prices were calculated by using the dollar denominated prices from the International Financial Corporation Emerging Markets database and the consumer price index data from the International Financial Statistics.

With these data we applied two straightforward tests to the log of the real stock prices: a variance ratio test and newer version of the standard Dickey-Fuller test. ${ }^{14}$ The variance ratio test results are reported in Tables 3 (the table reports the variance ratios for lag intervals of two, six and 12 months). These variance ratios should be close to one under the null hypothesis of a random walk. The results for the Dickey-Fuller test are reported in Table 4 and have a null hypothesis of a unit root.

The results show very similar results to the second camp described above. Specifically, we find that both tests generally show that stock prices generally behave as random walks before and after trade liberalization.

While these brief empirical results support our models conclusions during the post-trade liberalization period, they do not lend support to the models prediction that stock prices will be mean reverting in the pre-trade liberalization period. To this point we have two explanations. First, the tests that we are using to describe are of low power and consequently cannot accurately test for stationarity in the preliberalization period. Second, and more importantly, it is very possible that traders will realize the movement towards trade liberalization much before the announcement of such effects. Hence, the actual effect of trade liberalization may be coming well before the official trade liberalization dates that we used above. Only if it is possible to accurately date when traders became aware of the countrys commitment to open trade, can we truly test the models pre-liberalization conclusions.

\section{Conclusions}

This paper explores the effects of trade opening on emerging market stock returns. Trade opening is modeled as an elimination of a non-tariff restriction on the import of foreign intermediate inputs. In an autarkic environment where the

\footnotetext{
${ }^{14}$ The Dickey-Fuller test we use the autoregressive unit root test proposed by Elliott, Graham, and Stock (1996), which we refer to as the DF-GLS test. We use this test as it has been show to the highest power of the Dickey-Fuller unit roots tests. The DF-GLS test is a lower tail test and we reject the null hypothesis of a unit root if the test statistic is to the left of the critical value. The lags used are devised from the procedure of Newey and West (1994).
} 
Table 3. Variance Ratio Results

\begin{tabular}{|c|c|c|c|}
\hline Closed Countries & Lag $=2$ month & Lag $=6$ months & Lag $=12$ months \\
\hline Argentina & 0.99 & 0.92 & 0.84 \\
\hline Brazil & 1.00 & 0.90 & 1.04 \\
\hline India & 1.08 & 0.99 & 1.01 \\
\hline Mexico & 1.12 & $1.45^{*}$ & $2.06 * * *$ \\
\hline Nigeria & 1.01 & 0.81 & 0.79 \\
\hline Pakistan & 1.08 & 1.19 & 1.40 \\
\hline Philippines & $1.41 *$ & 1.39 & $2.12 *$ \\
\hline Venezuela & 1.12 & 1.32 & 1.10 \\
\hline Zimbabwe & $1.20 * * *$ & $1.95 * * *$ & $2.67 * *$ \\
\hline \multicolumn{4}{|l|}{ Open Countries } \\
\hline Argentina & 1.07 & 1.11 & 1.10 \\
\hline Brazil & 1.04 & 0.82 & 0.74 \\
\hline Chile & $1.16 * * *$ & $1.57 * * *$ & $2.00 * * *$ \\
\hline Colombia & $1.41 * * *$ & $1.80 * * *$ & $2.30 * * *$ \\
\hline Czech. & 1.07 & 0.62 & 0.81 \\
\hline Greece & $1.13^{*}$ & $1.35^{*}$ & $1.76 * * *$ \\
\hline Hungary & 0.95 & 0.84 & 1.02 \\
\hline India & 0.94 & 1.05 & 0.74 \\
\hline Indonesia & $1.28 * *$ & $1.55^{*}$ & $1.90 *$ \\
\hline Jordan & 1.01 & 1.11 & 1.08 \\
\hline Korea & 1.07 & 1.23 & 1.44 \\
\hline Malaysia & 1.13 & 1.35 & 1.51 \\
\hline Mexico & $1.34 *$ & 1.30 & 1.21 \\
\hline Morocco & $1.26^{*}$ & 1.54 & 1.52 \\
\hline Peru & 1.06 & 0.88 & 1.02 \\
\hline Philippines & $1.31 * * *$ & $1.58 * *$ & $1.70 *$ \\
\hline Poland & 1.09 & 1.36 & 1.59 \\
\hline Portugal & 1.26 & 1.62 & $2.10 * *$ \\
\hline South Africa & 0.99 & 0.92 & 1.02 \\
\hline Sri Lanka & 1.18 & 1.51 & $1.82 *$ \\
\hline Taiwan & 1.05 & 1.17 & 1.20 \\
\hline Thailand & 1.15 & 1.32 & $1.70 * *$ \\
\hline Turkey & 1.12 & $1.36^{*}$ & 1.50 \\
\hline Venezuela & 0.99 & 1.35 & $1.85^{* *}$ \\
\hline
\end{tabular}

***indicates significance at the 1 percent level using heteroscedastic robust $\mathrm{z}$-statistics

**indicates significance at the 5 percent level using heteroscedastic robust z-statistics

*indicates significance at the 10 percent level using heteroscedastic robust $\mathrm{Z}$-statistics

domestic production is starved due to lack of availability of complementary foreign intermediate inputs, technological economies scale are not reached and as a result diminishing returns to capital prevails. This technological inefficiency transmits to the financial sector. The stock market deviates from efficiency by displaying mean reverting behavior. As soon as the non-tariff barrier to the free flow of foreign 
Table 4. Dickey-Fuller Tests

\begin{tabular}{|c|c|c|}
\hline Closed Countries & Test Statistic & Lag Used \\
\hline Argentina & -1.12 & 8 \\
\hline Brazil & $-1.62 *$ & 8 \\
\hline India & 0.81 & 9 \\
\hline Mexico & $-1.84 *$ & 8 \\
\hline Nigeria & -1.45 & 9 \\
\hline Pakistan & -0.92 & 9 \\
\hline Philippines & -0.51 & 4 \\
\hline Venezuela & -1.61 & 4 \\
\hline Zimbabwe & $-2.07 * *$ & 12 \\
\hline \multicolumn{3}{|l|}{ Open Countries } \\
\hline Argentina & 0.31 & 7 \\
\hline Brazil & 0.03 & 7 \\
\hline Chile & 0.09 & 12 \\
\hline Colombia & -0.20 & 8 \\
\hline Czech. & -0.38 & 5 \\
\hline Greece & -1.13 & 12 \\
\hline Hungary & -0.86 & 5 \\
\hline India & -1.02 & 5 \\
\hline Indonesia & $-1.86^{*}$ & 7 \\
\hline Jordan & -0.03 & 10 \\
\hline Korea & -0.58 & 12 \\
\hline Malaysia & $-1.65^{*}$ & 9 \\
\hline Mexico & 0.08 & 8 \\
\hline Morocco & 0.05 & 4 \\
\hline Peru & -0.76 & 5 \\
\hline Philippines & -1.30 & 8 \\
\hline Poland & -0.43 & 5 \\
\hline Portugal & -0.20 & 8 \\
\hline South Africa & -0.56 & 5 \\
\hline Sri Lanka & -0.98 & 5 \\
\hline Taiwan & -0.25 & 9 \\
\hline Thailand & -0.96 & 12 \\
\hline Turkey & -1.00 & 7 \\
\hline Venezuela & $-1.70 *$ & 8 \\
\hline
\end{tabular}

***indicates significance at the 1 percent level

**indicates significance at the 5 percent level

*indicates significance at the 10 percent level

intermediate inputs is removed, the resulting technological efficiency manifests in terms of a random walk behavior of the stock market prices. We also establish that financial opening alone will not promote stock market efficiency. Trade reform in the form of removal of non-tariff barriers to imports intermediate inputs is just crucial because it translates technological efficiency to financial market efficiency. 
This theoretical analysis offers a testable hypothesis regarding the link between the productive efficiency and financial market efficiency. In terms of empirical support for our model, other researchers and our own results show that after trade liberalization, there is evidence that markets are efficient. However, we do not find sufficient evidence to indicate that the markets were not efficient before trade liberalization. This may be due to the power of the tests being used and or the fact that it is difficult to date when traders first incorporate their beliefs about the countrys commitment to trade opening.

\section{Acknowledgement}

The first author acknowledges Harald Uhlig and seminar participants at Tilburg University for helpful comments. We also benefited greatly from the comments of an anonymous referee. The usual disclaimer applies.

Received 11 November 2002, Accepted 4 November 2003

\section{References}

Bardhan, P., 1970, Economic Growth, Development and Foreign Trade, Wiley: New York, NY.

Basu, P., 1990, "A Martingale Theory of Asset Prices in a Production Economy", Mathematical Social Sciences, Vol.20, 1990, pp. 215-225.

Basu, P., H. Kawakatsu and M. Morey, "Liberalization and Stock Prices in Emerging Markets", Emerging Markets Quarterly, Fall 2000, 1-17.

Bekaert, G. and C. Harvey, 2000, "Foreign Speculators and Emerging Equity Markets", Journal of Finance, April, 565-613.

Bekaert, G., C. Harvey and C. Lundblad, 2001, "Does Financial Liberalization Spur Growth?", Duke University Working Paper.

Brock, W.A., 1982, “Asset Prices in a Production Economy," in J.J. McCall (ed.), The Economics of Information and Uncertainty, (University of Chicago Press, Chicago, IL), 1-83.

Bruno, M and J. Sachs, 1985, The Economics of Worldwide Stagflation, (Harvard University Press, Cambridge, MA).

Campbell, J.Y, 1994, "Inspecting the Mechanism: An Analytical Approach to the Stochastic Growth Model." Journal of Monetary Economics 33, 463-506.

Feenstra, R.C. and J.R. Markusen, 1994, "Accounting for Growth with New Inputs," International Economic Review, 35, pp. 429-447.

Henry, P.B., 2000a, "Stock Market Liberalization, Economic Reform, and Emerging Market 
Equity Prices," Journal of Finance, April, 529-564.

Henry, P.B., 2000b, "Do Stock Market Liberalizations Cause Investment Booms?" Journal of Financial Economics, October, 301-334.

Kawakatsu, H. and M. Morey, 1999a, "An Empirical Examination of Financial Liberalization and the Efficiency of Emerging Stock Market Prices", The Journal of Financial Research, 385-411, December, 1999.

Kawakatsu, H. and M. Morey, 1999b, "Efficiency in Emerging Stock Markets and Financial Liberalization: A Study of Nine Emerging Markets", The Journal of Multinational Financial Management, 353-372, November, 1999.

Kim, E.H. and V. Singal, 2000a, "Stock Market Openings: Experience of Emerging Economies". The Journal of Business, January, 25-66.

Kim, E.H., and V. Singal, 2000b, "The Fear of Globalizing Financial Markets", Emerging Markets Review, November, 183-198.

Lavhari, D and T.N. Srinivasan (1969), "Optimal Savings under Uncertainty," Review of Economic Studies, 36(2), 153-163.

Levine, R., N. Loayza and T. Beck (2000), "Financial Intermediation and Growth: Causality and Causes", Journal of Monetary Economics, 56, 134-156.

Lucas, R.E. Jr, 1978, “Asset Prices in an Exchange Economy,” Econometrica, Vol. 66, 1429-1445.

Lucas (1982), 1982, "Interest Rates and Currency Prcies in a Two-Country World," Journal of Monetary Economics, 10, pp. 335-359.

Manuelli, R. and Sargent, T.J., 1987, Exercises in Dynamic Macroeconomic Theory, (Harvard University Press, Boston, MA).

Newey, W. and K. West, 1994, "Automatic Lag Selection in Covariance Matrix Estimation”, Review of Economic Studies, 61, 4, 631-653.

Obstfeld, M and K. Rogoff, 1998, Foundations of International Macroeconomics, MIT Press.

Sachs, J. and A. Warner, 1995, "Economic Reform and the Process of Global Integration," Brookings Papers on Economic Activity, No. 1, 1-113. 


\section{Appendix 1}

Proof of Proposition 2: The social planning problem (2.P) is a special case of Campbell's (1994) log linear model with inelastic labor and with zero exogenous growth. Campbell shows that optimal consumption and capital accumulation policy rules are given by the following log linear difference equations:

$$
\begin{gathered}
c_{t}=\eta_{c k} k_{t}+\eta_{c a} a_{t} \\
k_{t+1}=\eta_{k k} k_{t}+\eta_{k a} a_{t}
\end{gathered}
$$

Plugging (A.2) into (2.22), and defining B as the backshift operator, we obtain,

$$
r_{t+1}=\left[\frac{1-\left(\eta_{k k}+\eta_{k a}\right) B}{\left(1-\eta_{k k}\right) B}\right] a_{t+1}
$$

Multiplying through by $\left(1-\eta_{\mathrm{kk}}\right) \mathrm{B}$ and rearranging terms, one obtains (2.24a). To obtain the stock price process plug (A.2) into (2.13).

Proof of Proposition 3: In the absence of any constraint on the availability of intermediate inputs, $\mathrm{V}_{\mathrm{t}}$ is set at the efficient level at which the marginal product of intermediate inputs exactly equals the world interest rate, $\mathrm{r}^{*}$, meaning that:

$$
\varepsilon_{\mathrm{t}} \mathrm{F}_{2}\left(\mathrm{~K}_{\mathrm{t}}, \mathrm{V}_{\mathrm{t}}^{*}\right)=\mathrm{r}^{*}
$$

Since $F\left(K_{t}, V_{t}\right)$ is linear homogenous in $K_{t}$ and $V_{t}$,

$\mathrm{F}_{\mathrm{v}}\left(\mathrm{K}_{\mathrm{t}}, \mathrm{V}_{\mathrm{t}}\right)=\mathrm{F}_{\mathrm{v}}\left(1, \mathrm{~V}_{\mathrm{t}} / \mathrm{K}_{\mathrm{t}}\right)$

Define $h\left(V_{t} / K_{t}\right)=F_{v}\left(K_{t}, V_{t}\right)$ as in (2.5). Notice that $h^{\prime}\left(V_{t} / K_{t}\right)<0$ which means $h($. is invertible. (A.4) thus reduces to:

$$
\mathrm{V}_{\mathrm{t}}^{*}=\mathrm{K}_{\mathrm{t}} \mathrm{h}^{-1}\left(\mathrm{r}^{*} / \varepsilon_{\mathrm{t}}\right)
$$

Upon substitution of (A.5) into the production function, $F\left(\mathrm{~K}_{t}, \mathrm{~V}_{t}\right)$ yields the following linear form of the production function:

$$
\mathrm{Y}_{\mathrm{t}}=\mathrm{F}\left(1, \mathrm{~h}^{-1}\left(\mathrm{r} * / \varepsilon_{\mathrm{t}}\right)\right) \mathrm{K}_{\mathrm{t}} \text {. }
$$

Plugging (A.5) and (A.6) into social planner's constraint (2.3) we get:

$$
\mathrm{C}_{\mathrm{t}}+\mathrm{K}_{\mathrm{t}+1}=\phi\left(\varepsilon_{\mathrm{t}}\right) \mathrm{K}_{\mathrm{t}}
$$

where $\phi\left(\varepsilon_{\mathrm{t}}\right)=\mathrm{F}\left(1, \mathrm{~h}^{-1}\left(\mathrm{r}^{*} / \varepsilon_{\mathrm{t}}\right)\right)-\mathrm{h}^{-1}\left(\mathrm{r}^{*} / \varepsilon_{\mathrm{t}}\right)+1-\delta$.

For the Cobb-Douglas production function, (2.16), 


$$
\phi\left(\varepsilon_{t}\right)=(1-\alpha) \alpha^{\frac{1}{1-\alpha}} r^{* \frac{\alpha}{1-\alpha}} \varepsilon_{t}^{\frac{1}{1-\alpha}}
$$

Recall from Lemma 2 that the ex post stock return equals investment return. This implies,

$$
\mathrm{R}_{\mathrm{t}+1}=\phi\left(\varepsilon_{\mathrm{t}+1}\right)
$$

Since $\left\{\varepsilon_{t}\right\}$ are serially uncorrelated, the stock returns $\left\{R_{t}\right\}$ are also serially uncorrelated.

To show that stock prices follow a random walk, we proceed as follows.

Step 1: When the utility function is CRRA as in (2.15) and shocks are i.i.d, the optimal investment function is as follows ${ }^{15}$ :

$$
\mathrm{K}_{\mathrm{t}+1}=\beta * \mathrm{~K}_{\mathrm{t}} \phi\left(\varepsilon_{\mathrm{t}}\right)
$$

where

$$
\beta^{*}=\beta\left[E\left\{\phi(\varepsilon)^{1-\gamma}\right\}\right]^{\frac{1}{1-\gamma}}
$$

Plugging this into the resource constraint (A.7), we get the optimal consumption policy rule as follows:

$$
C_{t}=\left(1-\beta^{*}\right) K_{t} \phi\left(\varepsilon_{t}\right)
$$

which means that the consumption follows a geometric random walk process as follows:

$$
C_{t+1}=\beta^{*} C_{t} \phi\left(\varepsilon_{t+1}\right)
$$

Since in equilibrium $C_{t}=D_{t}$, it follows that the dividend growth rates are i.i.d in a REE meaning,

$$
\frac{D_{t+1}}{D_{t}}=\beta^{*} \phi\left(\varepsilon_{t+1}\right)
$$

Step 2: Next note that the equilibrium asset pricing equation (2.2) for the household's problem (2.H) can be written as:

\footnotetext{
${ }^{15}$ the saving rule in this case follows the well known Levhari-Srinivasan (1969) form. For details see Manuelli and Sargent (1987).
} 


$$
\frac{P_{t}}{D_{t}^{\gamma}}=\beta E_{t}\left(\frac{P_{t+1}}{D_{t+1}^{\gamma}}\right)+\beta E_{t}\left(D_{t+1}^{1-\gamma}\right)
$$

Using (A.13) as the forcing process for dividend, it is straghtforward to verify that the solution to (A.14) is as follows:

$$
P_{t}=\frac{\bar{\beta}}{1-\bar{\beta}} D t
$$

where $^{16}$

$$
\bar{\beta}=\beta^{2-\gamma} E\left(\phi(\varepsilon)^{1-\gamma}\right)
$$

Next plugging (A.13) into the asset pricing equation (A.15), it follows that:

$$
P_{t+1}=\beta^{*} P_{t} \phi\left(\varepsilon_{t+1}\right)
$$

which means the stock price follows a geometric random walk.

Discussion of inequality (2.4): Proposition 2 demonstrates that open economies grow at a balanced rate, balanced rate, $\beta^{*} \phi\left(\varepsilon_{t+1}\right)$. Note from (A.7) that $\phi^{\prime}()>$.0 . Thus if $\bar{V}<V_{0}=\mathrm{K}_{0} \mathrm{~h}^{-1}\left(\mathrm{r}^{*} / \mathrm{a}\right)$, then $\mathrm{V}_{\mathrm{t}}{ }^{*}$ as defined in (A.5) will always be higher than $\bar{V}$.

\section{Appendix 2: A Model with Trade in Finished Goods}

We summarize here a variant of Lucas (1982) tree model with two goods. Consider a world economy with two countries, 1(home) and 2(foreign) having identical preferences. Country 1 citizens have $\mathrm{D}_{1}$ units of freely transportable goods, $\mathrm{x}$ and Country 2 citizens $\mathrm{D}_{2}$ units of freely transportable good $\mathrm{y}$. Assume that $\left\{D_{1 t}, D_{2 t}\right\}$ are stochastically varying over time, which are fruits from the trees of respective countries. Each agent in country i maximizes:

$$
E\left\{\sum_{t=0}^{\infty}\left[\frac{x_{i t}^{1-\gamma}}{1-\gamma}+\frac{y_{i t}^{1-\gamma}}{1-\gamma}\right], \quad 0<\beta<1\right.
$$

where $x_{i t}=i$ th country's consumption of good $x$ in country $i$ in period $t$, with $\mathrm{i}=1,2$, and $\mathrm{y}_{\mathrm{it}}=\mathrm{ith}$ country's consumption of good $\mathrm{y}$ in period $\mathrm{t}$. Since agents only

\footnotetext{
${ }^{16}$ In order to obtain the solution (A.15), one requires the convergence condition, $\bar{\beta}<1$. This imposes some restrictions on the model's parameters. Details are omitted for brevity but available from the authors upon request.
} 
differ only in terms of endowment, $D_{\text {it }}$, they will trade with each other. Since they are risk averse, they would perfectly pool the endowment risk by using the available stock markets. Perfect pooling of risks means agents in each country will trade in such a way that in equilibrium it consumes half of its home endowment, and half of foreign endowment. ${ }^{17}$ Under this perfect pooling of risk, the world economy becomes virtually identical to a closed economy as in Lucas (1978). Defining $\mathrm{P}_{\mathrm{xt}}$ as the current $\mathrm{x}$ unit price of stock, the home country's security valuation equation is:

$$
P_{x t} x_{1 t}^{-\gamma}=-\beta E_{t}\left\lfloor x_{1 t}^{-\gamma} \cdot\left(P_{x t+1}+D_{1 t+1}\right)\right\rfloor
$$

In a perfectly pooled equilibrium, $x_{1 t}=0.5 D_{1 t}$. It is straightforward to verify (following the same line of reasoning as in Lemma 3 ) that if home country's dividend growth rates $\left(\mathrm{D}_{1 \mathrm{t}+1} / \mathrm{D}_{1 \mathrm{t}}\right)$ are serially uncorrelated, then home country's stock prices follow a martingale.

In a two-country framework with trade in finished goods, stock market efficiency condition thus boils down again to zero serial correlations in home country's dividend growth rates. We have no explicit production here. However, production just imposes restriction on the process for dividend. We have already explored in section 2 of the paper that free flow of intermediate goods across the world makes the dividend growth rates serially uncorrelated. Thus as long as there is free flow of intermediate inputs, the main conclusion that stock market would be efficient holds even after allowing for trade in finished products.

\footnotetext{
${ }^{17}$ Endowments are equivalent to dividends here.
} 